\title{
USE OF GROUND PENETRATING RADAR TO STUDY SPATIAL VARIABILITY AND SOIL STRATIGRAPHY
}

\author{
José R. da R. Campos ${ }^{1 *}$, Pablo Vidal-Torrado², Alcir J. Modolo ${ }^{3}$
}

${ }^{1 *}$ Corresponding author. Universidade Tecnológica Federal do Paraná - UTFPR/ Pato Branco - PR, Brasil.

E-mail: jrcampos@utfpr.edu.br | ORCID ID: https://orcid.org/0000-0002-5162-3158

\section{KEYWORDS}

Geophysics, soil stratigraphy, agricultural engineering.

\begin{abstract}
Ground Penetrating Radar (GPR) is a geophysical method that uses electromagnetic waves to study subsurface structure in different fields such as geology, agriculture and civil engineering. The wave penetration in the soil is strongly controlled by the electrical conductivity of soil components such as clay, organic matter, and water. In this study, tests were conducted in a floodplain in the Elizabeth Creek watershed (New Jersey USA). We established one transect where measurements were completed using two techniques, common mid point (CMP) and constant offset profile (COP), both with 100$\mathrm{MHz}$ frequency antennas. Measurements were also completed using 250 and $500 \mathrm{MHz}$ shielded antennas. GPR showed good accuracy to study soil spatial variability and stratigraphy. Antennas of a higher frequency had less vertical investigation capacity and greater accuracy. In this study, it was not possible to clearly differentiate signals from organic matter and clay; this was the main limitation of the GPR system.
\end{abstract}

\section{INTRODUCTION}

Ground Penetrating Radar (GPR) is a geophysical method that uses radio waves to study subsurface structure in different fields such as geology, civil engineering, and agronomy. The most common GPR configuration has transmitting and receiving antennas connected by an optical fiber cable with a data processing system that computes the elapsed time of the wave generated at the transmitting antenna and arriving at the receiving antenna (Daniels, 2004; Doolittle et al., 2007; Comas et al., 2015).

The soil exploration capacity of GPR is determined by the antenna frequency and soil properties (Olhoeft, 1998; Daniels, 2004; Fernandez \& Rocha, 2014). Because of its high attenuation rate, wave penetration in the soil is strongly reduced under conditions of high electrical conductivity related to clay. water, and organic matter content. All these features are strongly influenced by the parent material, climatic conditions, topography, and biological activity (Daniels, 2004; Tran et al., 2015; Forte \& Pipan, 2017).

All materials in the subsurface have some type of free electric charge and, therefore, some degree of attenuation of an electromagnetic (EM) field. Electrical permittivity describes the ability of a material to store and release EM energy as an electric charge. Electrical conductivity is the ability of a material to pass free electric charge under the influence of an applied field (Afshar et al., 2015; Comas et al., 2015; Tran et al., 2015).

In agriculture, GPR has been used in different areas such as irrigation, mechanization, and pedology; its main advantage is that it represents a noninvasive technique of high resolution. In Italy, Rossi et al. (2015) used GPR to analyze the water percolation process on soil. Campos et al. (2016) used this technique to analyze groundwater depth and the influence of geological structure on water flow. Several studies have been developed to analyze soil compaction, map shallow soils, and prevent damage during its implementation (Ciampalini et al., 2015; Campos et al., 2016). In addition, this equipment has been used to monitor moisture content and water infiltration in irrigated fields (Rossi et al., 2015; Tran et al., 2015).

In the Elizabeth Creek watershed (New Jersey, USA), the entire area is monitored by piezometers and seismic sensors installed at different soil depths. The chemical and physical characteristics of the water and the dynamics of hydrologic flows on the soil are permanently

${ }^{2}$ Escola Superior de Agricultura Luiz de Queiroz - Esalq/USP/ Piracicaba - SP, Brasil.

${ }^{3}$ Universidade Tecnológica Federal do Paraná - UTFPR/ Pato Branco - PR, Brasil.

Received in: 3-26-2018

Accepted in: 3-11-2019 
monitored. These apparatuses limit the possibilities of opening trenches or introducing other techniques capable of measuring soil fluid flows. However, GPR represents a valuable technology because it is designed to penetrate the ground and provide images at 0 to $30 \mathrm{~m}$ soil depth (Rossi et al., 2015). Within this context, the objective of this study was to evaluate the accuracy of GPR to study the spatial variability and soil stratigraphy of a floodplain along the Elizabeth River, New Jersey, USA.

\section{MATERIAL AND METHODS}

The study area was the Elizabeth Creek watershed, New Jersey, USA, (Figure 1). Data were collected during April 2013. The area is a floodplain subdivided into distal and proximal plains. The distal plain presents hydromorphic features of groundwater outcropping and high organic matter (OM) content in the top $20 \mathrm{~cm}$ of soil, whereas the proximal plain is well-drained and has low OM content.

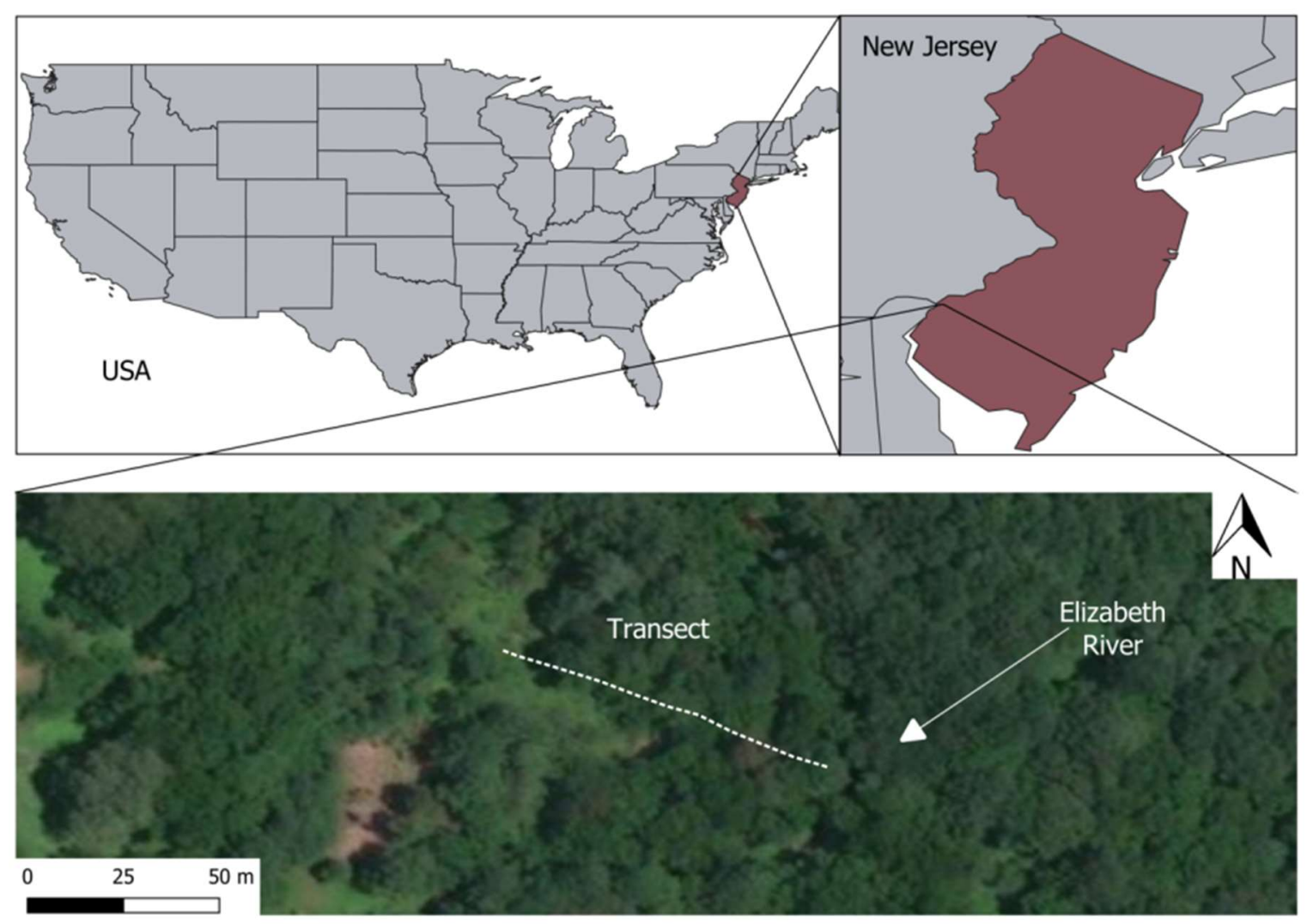

FIGURE 1. Locality of the study area.

Measurements were completed on a transect starting from the Elizabeth Creek bank stretching to the beginning of the hillside (79 meters) (Figure 2A). We used a GPR system with $100-\mathrm{MHz}$ frequency antennas and the common midpoint profile (CMP) technique in which the antennas are moved in the opposite direction at a $5 \mathrm{~cm}$ interval (Figure 2B) (Annan, 2009; Plado et al., 2011; Comas et al., 2015). Measurements were also completed based on the constant offset profile (COP) where the system is mounted with a $1 \mathrm{~m}$ distance between antennas (Figure 3C). Measurements were also completed using two shielded antennas (250 and $500 \mathrm{MHz})$ with a distance between two antennas of $30 \mathrm{~cm}$. The antennas used in the present study were manufactured by the Malã Geoscience company.
Following the field campaign, radargrams were processed in the laboratory using filters such as: static correction, dewow, gain, migration, and topographic correction available in the $2 \mathrm{D}$ reflex software. The static correction offers the possibility of automatically determining the first significant arrival and correcting the start position of the time axis to this phase. The internal input parameters were fixed to a threshold of $10 \%$ of the maximum existing amplitude value and the dominant frequency of the wavelet. The dewow filter eliminated the low-frequency noises which occurred in the GPR data when there was induction of electric current in the antenna circuit. For each trace, it calculated the mean of the points on either side of that point within a specified time range. Then, the mean was subtracted from the original point (Bradley et al., 2009). 


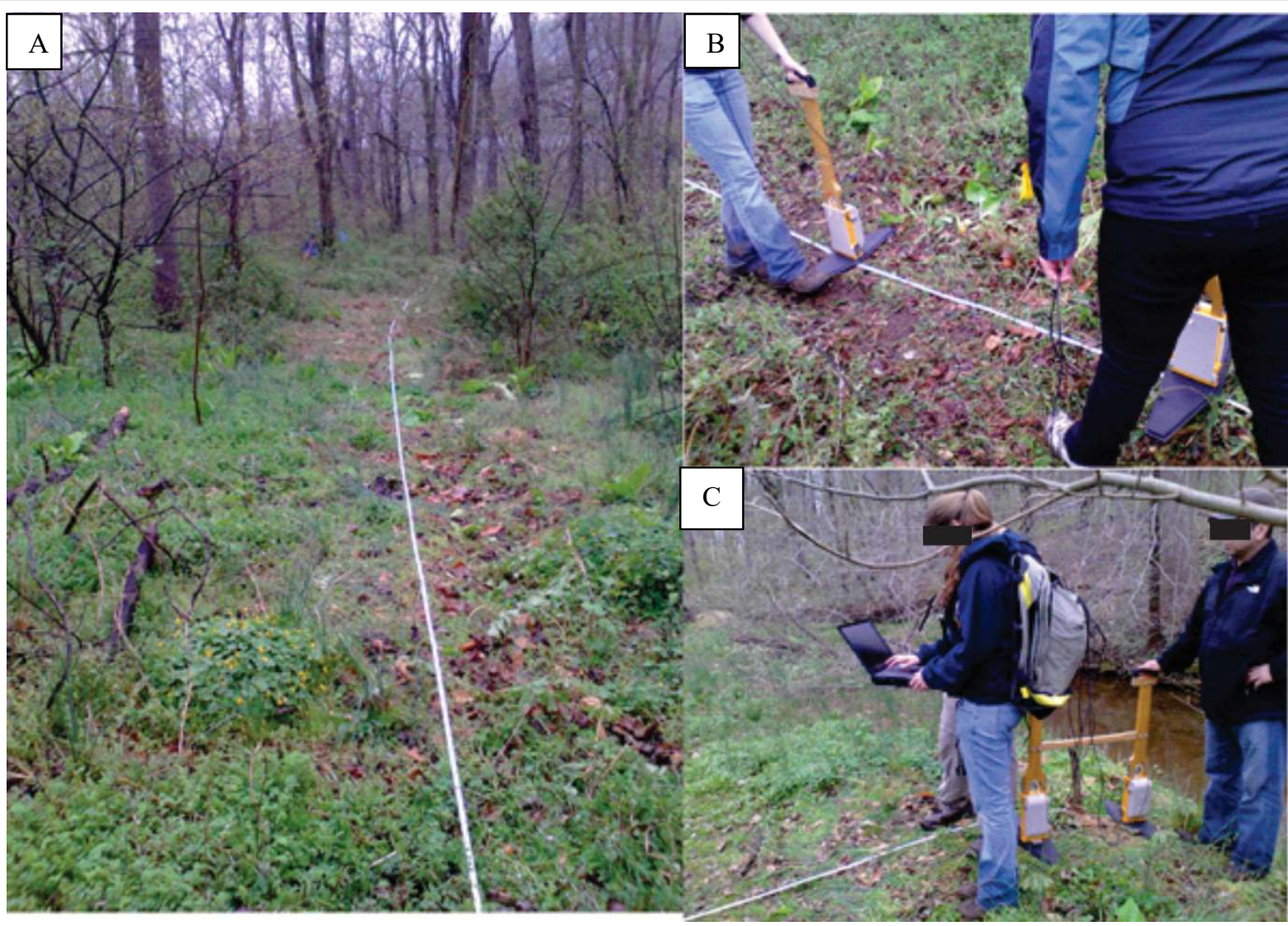

FIGURE 2. Field campaign in the Elizabeth Creek watershed in New Jersey, USA. A) Location where measurements were completed using GPR; B) Measurements using the CMP method; and C) Measurements using the COP method.

The gain function step helped to visualize data late in the time series of each trace. As the results of the signal dispersion and attenuation, the returned signal at longer two-way travel times will naturally be lower in amplitude and therefore more difficult to identify and interpret. Applying a gain will amplify the data; therefore, it is important to choose the appropriate gain function to avoid introducing artifacts into the dataset (Daniels, 2004). The goal of migration is to track back the reflection and diffraction energies to their "source". A zero offset section often does not represent the "true" position of the reflectors, particularly in the presence of steep layers. Following the migration, a better approximation of the subsurface is often provided. If strong diffractions are present, the migration attempts to constrict these diffractions to a minimum. This is useful, for example, for interpretations that use time slices (Daniels, 2004). Topographic correction adjusts the reflector locations for any topographic variation along the survey line. Topographic data were collected using a total station.

In general, GPR calculates the time spent by an EM wave pulse to reach an interface between materials with different physical characteristics and arrive back to the receiving antenna. Thus, from data processing, we calculated the EM wave propagation velocity of different soil layers. Values of time and distance between antennas were used to generate a linear regression and calculate wave propagation velocities using the inverse of the slope (Daniels, 2004; Mount et al., 2015). The dielectric permittivity of the different materials was calculated using $\mathrm{v}=0.3 / \sqrt{ } \varepsilon_{\mathrm{r}}$ (Daniels, 2004; Mount et al., 2015; Tran et al., 2015), where $\mathrm{v}$ is the velocity of wave propagation, 0.3 is a constant, and $\varepsilon_{\mathrm{r}}$ is the relative dielectric permittivity.

Following the measurements using GPR, soundings in both features (the distal and proximal plains) were completed and soil samples were collected for stratigraphic characterization. The soil color was analyzed using the Munsell Soil Color Chart. A stratigraphic profile was prepared according to the methodology proposed by Bridge (2006) and Ford et al. (2007).

\section{RESULTS AND DISCUSSION}

In the distal plain, the first soil layer $(0-56 \mathrm{~cm})$ is represented by a reflected wave (RW) (Figure $3 \mathrm{~B})$. We found a very low $\mathrm{v}$ (wave propagation velocity) and high $\varepsilon_{\mathrm{r}}$ (dielectric permittivity) typical of hydromorphic soils with high OM content (Plado et al., 2011; Comas et al., 2015). The values of $\mathrm{v}$ and $\varepsilon_{\mathrm{r}}$ were $0.035 \mathrm{~m} \mathrm{~ns}^{-1}$ and 66.35 , respectively (Table 1), similar to the results observed for the proximal plain. 
A

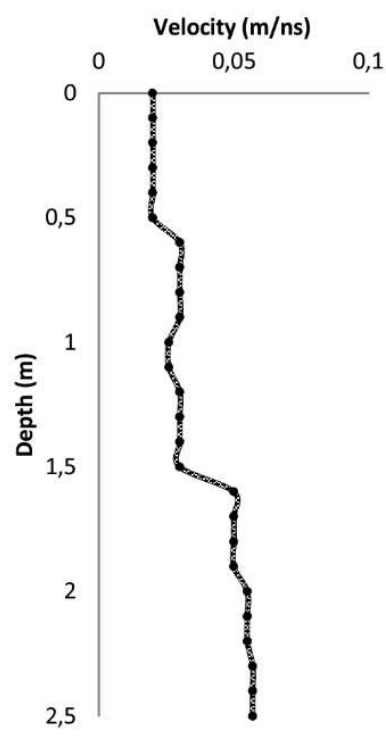

B

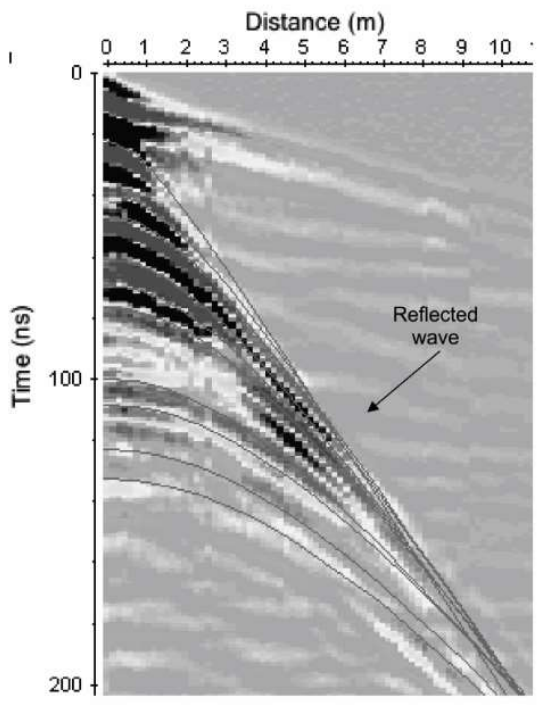

C

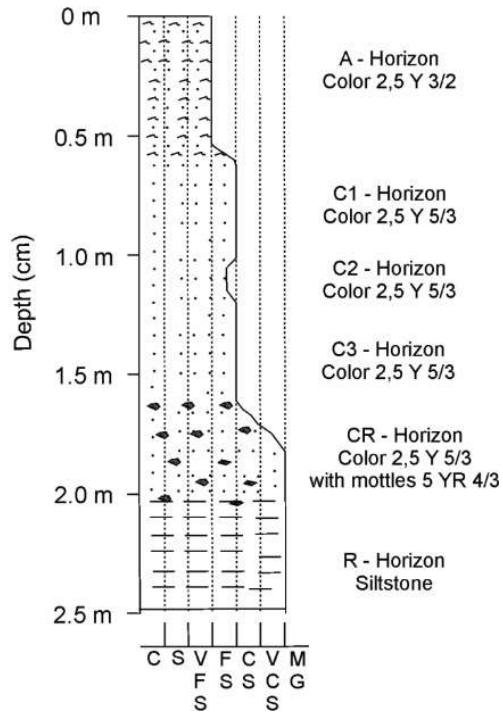

FIGURE 3. Wave propagation velocity model in the soil (A): radargram generated using the CMP method (B); and stratigraphic profile generated by soundings and characterization of samples from the distal plain (C).

The second layer, between 56 and $110 \mathrm{~cm}$, had $\mathrm{v}$ values higher than those from the upper layer. The value of $\varepsilon_{\mathrm{r}}$ was 39.87 , suggesting a reduction in the water and $\mathrm{OM}$ contents in this layer (Afshar et al., 2015; Tran et al., 2015). The $v$ value was slightly reduced in the third layer

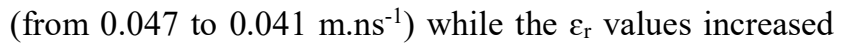
from 39.87 to 52.41 , suggesting a further increase in water content, somewhat expected because the area consists of a sedimentary floodplain.

The fourth layer $(122-160 \mathrm{~cm})$ showed strong similarities with the second layer because the $\mathrm{v}$ and $\varepsilon_{\mathrm{r}}$ parameters were the same. The variations observed in the other subsequent layers were lower than those observed in the surface layers because they are layers of the basement rocks (siltstones) (Afshar et al., 2015; Fernandez \& Rocha, 2014). Results obtained using GPR in the proximal plain were similar to those obtained in the distal plain and corroborate the stratigraphic profile generated by the soundings. Four layers were observed. The first and second layers (Figure 3C) are thicker than the first and second layers of the soil profile from the distal plain. However, the third layer is thicker in relation to the proximal plain. The sounding was unable to reach the end of the fourth layer.

TABLE 1. Characteristics of stratigraphic layers found in the distal plain of the Elizabeth Creek watershed, New Jersey, USA.

\begin{tabular}{|c|c|c|c|c|}
\hline Reflected waves/ Layers & $\mathrm{Eq}^{1}$ & $\begin{array}{c}\mathrm{v}^{2} \\
\left(\mathrm{~m} \cdot \mathrm{ns}^{-1}\right)\end{array}$ & $\varepsilon_{\mathrm{r}}{ }^{3}$ & $\begin{array}{c}\text { Depth } \\
(\mathrm{cm})\end{array}$ \\
\hline RW ${ }^{4} .1$ - Soil & $y=737.25 x+2130$ & 0.035 & 66.35 & $0-56$ \\
\hline $\mathrm{RW}^{4} .2$ - Soil & $y=443.02 x+6947,9$ & 0.047 & 39.87 & $56-110$ \\
\hline $\mathrm{RW}^{4} .3$ - Soil & $y=582.4 x+7457,6$ & 0.041 & 52.41 & $110-122$ \\
\hline $\mathrm{RW}^{4} .4$ - Soil & $y=448.44 x+10524$ & 0.047 & 40.35 & $122-160$ \\
\hline RW 4.5 - Soil & $y=389.02 x+14025$ & 0.050 & 35.01 & $160-190$ \\
\hline RW ${ }^{4} .6$ - saprolite & $y=411.71 x+17250$ & 0.055 & 29.75 & $190-290$ \\
\hline
\end{tabular}

${ }^{1}$ Equation of reflected waves generated using the CMP method; ${ }^{2}$ Wave propagation velocity in the soil; ${ }^{3}$ Dielectric permittivity of soils from a proximal plain of the Elizabeth Creek watershed; ${ }^{4} \mathrm{RW}$ is the reflected wave. 
In the proximal plain, the wave propagation velocity model developed from the corresponding CMP (Figure 4A) showed a tendency of increasing wave propagation velocity with increasing soil depth. Each RW (Figure 4B) represents an interface between layers with distinct physical characteristics (Daniels, 2004; Doolittle et al., 2007; Plado et al., 2011).

A

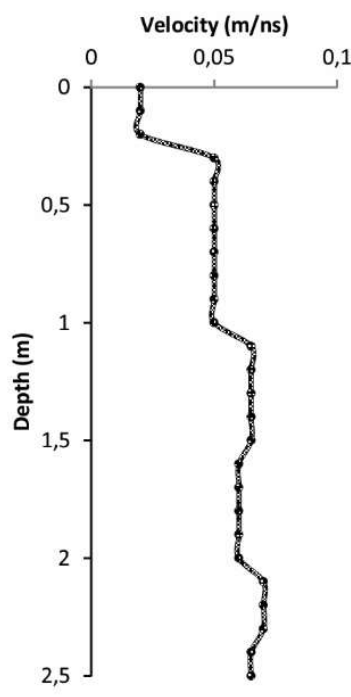

B

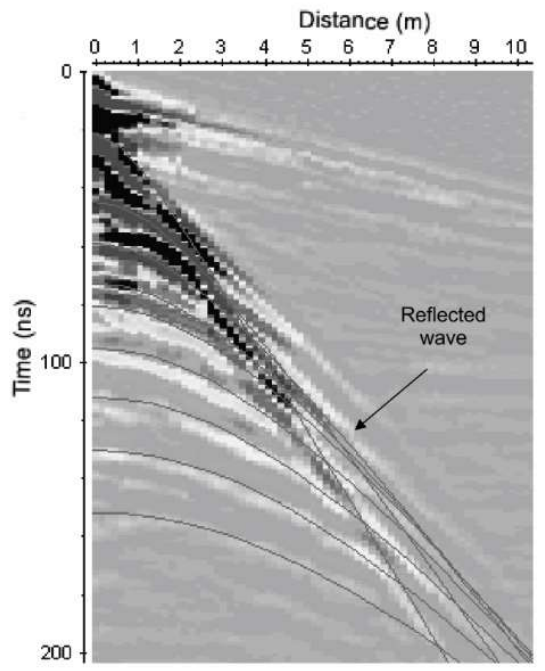

C

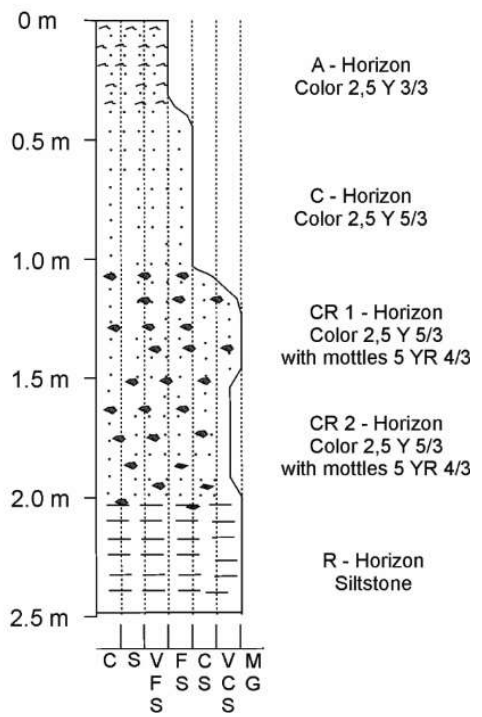

FIGURE 4. Wave propagation velocity model in the soil (A): radargram generated using the CMP method (B) and stratigraphic profile generated by soundings and characterization of samples $(\mathrm{C})$ in the proximal plain.

The first soil layer $(0-40 \mathrm{~cm})$ represented by reflected wave 1 (Figure 4A) shows lower values of $\mathrm{v}$ and high values of $\varepsilon_{\mathrm{r}}\left(0.036 \mathrm{~m} . \mathrm{ns}^{-1}\right.$ and 69,44 , respectively) (Table 2). These characteristics are consequences of the high water content observed in this layer. The high electric charge content and the high water retention capacity of the
OM have a great influence on the attenuations of the GPR signal (Wijewardana \& Galagedara, 2010; Comas et al., 2015; Tran et al., 2015). If there are available charges, under the influence of an EM field, they will flow over the material resulting in attenuation and energy loss (Plado et al., 2011; Afshar et al., 2015).

TABLE 2. Characteristics of stratigraphic layers found in the lowland proximal plain of the Elizabeth Creek watershed, New Jersey, USA.

\begin{tabular}{ccccc}
\hline $\begin{array}{c}\text { Reflected waves/ } \\
\text { Layers }\end{array}$ & $\mathrm{Eq}^{1}$ & $\begin{array}{c}\mathrm{v}^{2} \\
\left(\mathrm{~m}_{\mathrm{n}} \mathrm{ns}^{-1}\right)\end{array}$ & $\varepsilon_{\mathrm{r}}{ }^{3}$ & $\begin{array}{c}\text { Depth } \\
(\mathrm{cm})\end{array}$ \\
\hline $\mathrm{RW}^{4}$. 1 - Soil & $\mathrm{y}=737.25 \mathrm{x}+2130$ & 0.036 & 69.44 & $0-40$ \\
$\mathrm{RW}^{4}$. - Soil & $\mathrm{y}=605.28 \mathrm{x}+3502.3$ & 0.046 & 42.53 & $41-110$ \\
$\mathrm{RW}^{4}$. 3 - saprolite & $\mathrm{y}=367.58 \mathrm{x}+6416.1$ & 0.062 & 23.41 & $111-150$ \\
$\mathrm{RW}^{4}$. 4 - saprolite & $\mathrm{y}=412.46 \mathrm{x}+7955$ & 0.060 & 24.99 & $151-195$ \\
$\mathrm{RW}^{4}$. 5 - saprolite & $\mathrm{y}=480.85 \mathrm{x}+9982.4$ & 0.065 & 21.03 & $196-220$ \\
$\mathrm{RW}^{4}$. 6 - saprolite & $\mathrm{y}=345.59 \mathrm{x}+15286$ & 0.060 & 24.99 & $220+$ \\
\hline
\end{tabular}

${ }^{1}$ Equation of reflected wave generated using the CMP method; ${ }^{2}$ Wave propagation velocity in the soil; ${ }^{3}$ Dielectric permittivity of soil from the proximal plain of the Elizabeth Creek watershed; ${ }^{4} \mathrm{RW}$ is the reflected wave.

The lack of an interface between 40 and $110 \mathrm{~cm}$ (Figure 4A) shows that, within this range, the soil physical and chemical characteristics are similar. In relation to the overlying layer, $\mathrm{v}$ values increased from 0.036 to 0.046 m.ns ${ }^{-1}$ while $\varepsilon_{\mathrm{r}}$ values decreased from 69.44 to 42.53 , suggesting a reduction in the $\mathrm{OM}$ content in relation to the overlying layer (Wijewardana \& Galagedara, 2010; Plado et al., 2011; Afshar et al., 2015).

Between 110 and $150 \mathrm{~cm}$ (Figure 4B), the $\mathrm{v}$ values

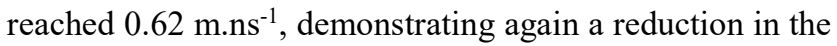
$\mathrm{OM}$, water, and clay content. In this layer, there was no significant variations in $\mathrm{v}$ and $\varepsilon_{\mathrm{r}}$ until $3.9 \mathrm{~m}$; however, some interfaces were still observed (Figure 4A). The existence of these interfaces is related to the layering of the thin weathered siltstone that is dominant in this area.

Observations from GPR were similar to those obtained by the stratigraphic profile generated by the soundings. Four layers were observed. The first layer showed a dark color (2.5 Y 3/3) (Figure 4C) and fine texture compared to that of the layer below. The second layer is quite homogeneous, presenting a predominance of gray-colored coarse sands. The third layer showed a coarse 
sand matrix with rock fragments and mottles while the bottom layer showed resistant rocks (siltstone). The main limitation of the GPR method is that it is not possible to differentiate signals from organic matter, clay, and water. These parameters all result in high attenuation of GPR signals.

From the aforementioned model and using radargrams generated with shielded antennas (100, 250, and $500 \mathrm{MHz}$ ), it was possible to generate models that represent the stratigraphy of the area and the lateral distribution of the different landscape components (Figure 5) (Plado et al., 2011). The resolution differs according to the frequency of the antenna (Wijewardana \& Galagedara, 2010; Tran et al., 2015). Antennas of a higher frequency have a higher resolution and lower depth range, while lower frequency antennas have a larger range and depth but of a lower resolution (Wijewardana \& Galagedara, 2010; Tran et al., 2015).
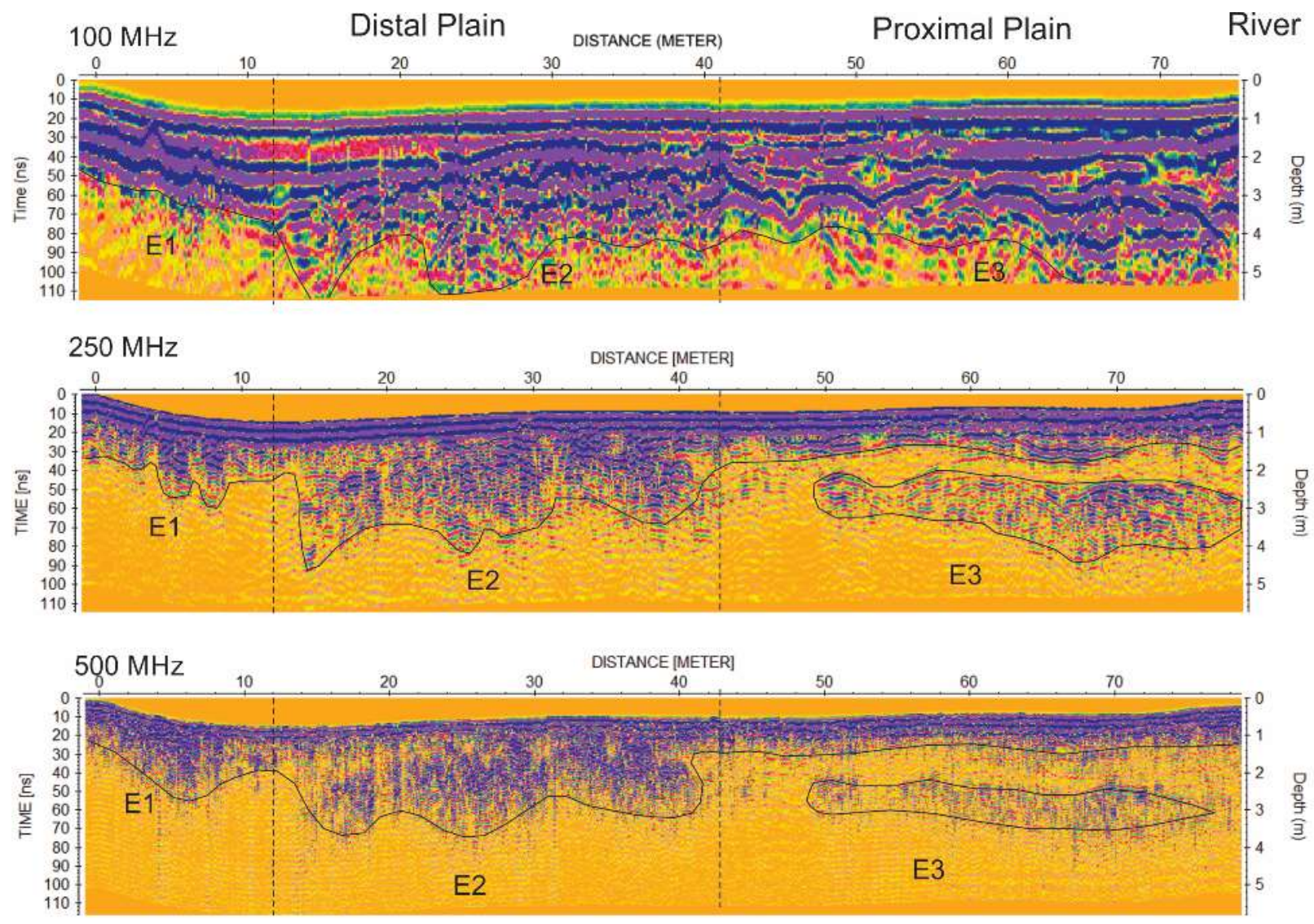

FIGURE 5. Radargrams generated using the GPR system with offset antennas (100 MHz frequency) (A) and shield antennas of a $250-\mathrm{MHz}$ frequency (B) and 500-MHz frequency (C) in the Elizabeth Creek watershed, New Jersey, USA.

From the radargrams, it was possible to determine three environments with distinct characteristics: Environment 1 (E1), at the beginning of the half-slope, where shallow and underdeveloped soils dominate (for example, Inceptisols and Entisols). Towards the river, Environment 2 (E2), on the distal plain, where there is a deeper soil layer rich in organic matter and clay, favorable for the formation of the Mollisols. This characteristic is typical of a distal plain because it includes elevations slightly lower in relation to the surroundings. Because it is at a major distance from the river, it tends to be a more humid environment and richer in organic matter and clay (Bridge, 2006; Ford et al., 2007). In the proximal plain, closer to the river, a more stratified environment (E3) has formed via deposition of sediments varying between organic/clay rich and sandy supplied by the river. The predominant soils in this portion are largely Entisols (Fluvent) (Bridge, 2006; Ford et al., 2007).

Although the results of the present study were satisfactory, it is important to highlight that research remains lacking that would facilitate GPR becoming even more applicable in areas such as irrigation and agricultural land capacity analysis, among others.

\section{CONCLUSIONS}

In the present study, a GPR system showed good accuracy in studying the spatial variability and soil stratigraphy. However, in a landscape where organic matter occurs in association with clay, such as in distal plains, it is not possible to clearly differentiate signals from each of the different materials.

\section{ACKNOWLEDGMENTS}

The authors wish to thank the São Paulo Research Foundation (FAPESP) Project \# 2011/21191-3 and the National Council for Scientific and Technological Development (CNPq) Project \# 482815/2011-6 for their financial support. 


\section{REFERENCES}

Afshar A, Abedi M, Norouzi G, Riahi M (2015)

Geophysical investigation of underground water content zones using electrical resistivity tomography and ground penetrating radar: A case study in Hesarak-Karaj, Iran. Engineering Geology 196:183-193.

Annan AP (2009) Electromagnetic Principles of Ground Penetrating Radar. In: Jol HM (ed). Ground Penetrating Radar: Theory and Application. Amsterdam, Elsevier, p.3-37.

Bradley MB, Adrian A, Camelia K (2009) Empirical mode decomposition operator for dewowing GPR data. Journal of Environmental and Engineering Geophysics (14):163169. DOI: $10.2113 /$ JEEG14.4.163

Bridge J (2006) Fluvial facies models: Recent developments. In: Posamentier HW, Walker RG (eds). Facies models revisited. Tulsa, SEPM, p. 85-170.

Campos JRR, Silva AC, Slater L, Nanni MR, VidalTorrado P (2016) Stratigraphic control and chronology of peat bog deposition in the Serra do Espinhaço Meridional, Brazil. Catena (143):167-173.

Ciampalini A, André F, Garfagnoli F, Grandjean G, Lambot S, Chiarantini L, Moretti S (2015) Improved estimation of soil clay content by the fusion of remote hyperspectral and proximal geophysical sensing. Journal of Applied Geophysics 116:135-145.

Comas X, Terry N, Slater L, Warren M, Kolka R, Kristiyono N, Sudiana N, Nurjaman D, Darusman T (2015) Imaging tropical peatlands in Indonesia using ground-penetrating radar (GPR) and electrical resistivity imaging (ERI): implications for carbon stock estimates and peat soil characterization. Biogeosciences 12:2995-3007.

Daniels DJ (2004) Ground penetrating radar. London, The Institute of Electrical Engineers, $2^{\text {nd }}$ ed. $726 \mathrm{p}$.

Doolittle JA, Minzenmayer FE, Waltman SW, Benhamd EC, Tuttle JW, Peaslee SD (2007) Ground-penetrating radar soil suitability map of the conterminous United States. Geoderma 141: 416-421.
Fernandez GB, Rocha TB (2014) Radar de penetração do solo (GPR) aplicado a geomorfologia costeira: Potencialidades e limitações. Revista Geonorte 10(1):129-134.

Ford M, Williams EA, Malartre FM, Popescu S (2007) Stratigraphic architecture, sedimentology and structure of the Vouraikos Gilbert-type fan delta, Gulf of Corinth, Greece, In: Nichols G, Williams E, Paola C (eds). Sedimentary Processes, Environments and Basins: A Tribute to Peter Friend. Oxford, International Association of Sedimentologists, Blackwell Publishing, p.53-90.

Forte E, Pipan M (2017) Review of multi-offset GPR applications: Data acquisition, processing and analysis. Signal Processing 132:210-220.

Mount GJ, Comas X, Wright WJ, McClellan MD (2015) Delineation of macroporous zones in the unsaturated portion of the Miami limestone using ground penetrating radar, Miami Dade County, Florida. Journal of Hydrology 527:872-883.

Olhoeft G (1998) Electrical, magnetic, and geometric properties that determine ground penetrating radar performance. In: International Conference on Ground Penetrating Radar. Lawrence. Proceedings...

Plado J, Sibul I, Mustasaar M, Jõeleht A (2011) Groundpenetrating radar study of the Rahivere peat bog, eastern Estonia. Estonian Journal of Earth Sciences 60(1):31-42.

Rossi M, Manoli G, Pasetto D, Deiana R, Ferraris S, Strobbia C, Putti M, Cassiani G (2015) Coupled inverse modeling of a controlled irrigation experiment using multiple hydro-geophysical data. Advances in Water Resources 82:150-165.

Tran AP, Bogaert P, Wiaux F, Vanclooster M, Lambot S (2015) High-resolution space-time quantification of soil moisture along a hillslope using joint analysis of ground penetrating radar and frequency domain reflectometry data. Journal of Hydrology 523:252-261.

Wijewardana YGNS, Galagedara LW (2010) Estimation of spatio-temporal variability of soil water content in agricultural fields with ground penetrating radar. Journal of Hydrology 391:24-33. 